\title{
Pre-pregnancy care for women with pre-gestational diabetes mellitus: a systematic review and meta-analysis
}

\author{
Hayfaa A Wahabi", Rasmieh A Alzeidan and Samia A Esmaeil
}

\begin{abstract}
Background: Pre-gestational diabetes mellitus is associated with increased risk for maternal and fetal adverse outcomes. This systematic review was carried out to evaluate the effectiveness and safety of pre-pregnancy care in improving the rate of congenital malformations and perinatal mortality for women with pre-gestational diabetes mellitus.

Methods: We searched the following databases, MEDLINE, EMBASE, WEB OF SCIENCE, Cochrane Library, including the CENTRAL register of controlled trials and CINHAL up to December 2011, without language restriction, for any pre-pregnancy care aiming at health promotion, glycemic control and screening and treatment of diabetes complications in women with type I or type II diabetes mellitus. Study design were trials (randomized and nonrandomized), cohort and case-control studies.

Results: Of the 2452 title scanned 54 full papers were retrieved of those 21 studies were included in this review. Twelve cohort studies at low and medium risk of bias, with 3088 women, were included in the meta-analysis. Meta-analysis suggested that pre-pregnancy care is effective in reducing congenital malformation, Risk Ratio (RR) 0.25 (95\% Cl 0.16-0.37), number needed to treat (NNT) 19 (95\% Cl 14-24), and perinatal mortality RR 0.34 (95\% Cl $0.15-0.75), \mathrm{NNT}=46$ (95\% Cl 28-115).

Pre-pregnancy care lowers glycosylated hemoglobin A1c ( $\mathrm{HbA1c}$ ) in the first trimester of pregnancy by an average of $1.92 \%(95 \% \mathrm{Cl}-2.05$ to -1.79$)$. However women who received pre-pregnancy care were at increased risk of hypoglycemia during the first trimester of pregnancy RR 1.51 ( $95 \% \mathrm{Cl} 1.15-1.99)$.

Conclusion: Pre-pregnancy care for women with pre-gestational type 1 or type 2 diabetes mellitus is effective in improving rates of congenital malformations, perinatal mortality and in reducing maternal $\mathrm{HbA1C}$ in the first trimester of pregnancy. Pre-pregnancy care might cause maternal hypoglycemia in the first trimester of pregnancy.

Keywords: Pre-gestational diabetes, Pre-pregnancy care, Congenital malformations, Perinatal mortality
\end{abstract}

\section{Background}

Pre-gestational diabetes mellitus (PGDM) and maternal hyperglycemia during the time of organogenesis is a known teratogen with detrimental effects on the fetal heart, renal, musculoskeletal and central nervous systems [1-3]. Population based studies showed that there is a fivefold increase in the rate of cardiovascular malformations, and more than twofold increase in the rate of neural tube

\footnotetext{
* Correspondence: umlena@yahoo.com

Sheikh Bahmdan Chair of Evidence-based Healthcare and Knowledge

Translation, College of Medicine, King Saud University, Riyadh, Saudi Arabia
}

defects and urinary tract abnormalities in infants of diabetic mothers when compared to the background population $[1,2]$. Moreover congenital malformations (GM) are associated with increased risk of stillbirth and perinatal mortality (PM) as they account for almost $50 \%$ of all deaths of infants born to mothers with PGDM [4,5].

$\mathrm{CM}$ secondary to maternal diabetes can be prevented, in great part, by optimizing maternal health in the prepregnancy period. Glycemic control is one of the most important aspects of pre-pregnancy care (PPC) [6]; however other aspects of care such as folic acid supplementation, smoking cessation, screening and treatment of diabetes 
complications and discontinuing teratogenic medications, are as important for improving maternal and fetal outcomes and might be effective in reducing the rate of $\mathrm{CM}$ to the background level [7-9].

The aim of this systematic review is to assess the effectiveness and safety of PPC in improving the CM and perinatal mortality for women with type 1 or type 2 PGDM.

\section{Methods}

\section{Type of studies}

We included in this review randomized trials (including cluster and quasi randomized trials) and cohort and case control studies, comparing the frequency of CM, PM, maternal hypoglycemia in the first trimester and the level of glycosylated hemoglobin A (HbA1C) in diabetic women who received PPC with those who did not receive PPC.

\section{Type of participants}

Women of reproductive age with type 1 or type 2 PGDM who were not pregnant at the time of intervention.

\section{Type of intervention}

For the purpose of this review PPC is defined as the following either as sole intervention or in combination

1. Glycemic control by insulin and/or diet aiming at fasting blood glucose $\leq 5.7 \mathrm{mmol} / \mathrm{l}$ or/and postprandial blood glucose $\leq 7.8 \mathrm{mmol} / \mathrm{l}$ and/ or $\mathrm{HbA} 1 \mathrm{C} \leq 7.0 \%$ ).

2. Women counseling and /or education about diabetes complications during pregnancy, the importance of glycemic control and self monitoring of blood glucose level.

3. Pre-pregnancy screening and treatment of complications of diabetes.

4. The use of contraception until optimization of glycemic control is achieved.

5. Intake of multivitamin or folic acid in the pre-pregnancy period.

\section{Type of outcome}

Maternal outcomes

1. HbA1C level in the first trimester.

2. Maternal hypoglycemia in the first trimester or any other adverse effect reported by the authors.

Neonatal outcomes

1. CM related to maternal diabetes

2. Perinatal mortality.

\section{Exclusion criteria}

We excluded from this review reports which are not of comparative design and reports of conference proceedings or abstracts when there is no complete description of the trial or study.

\section{Search strategy}

The search strategy was developed in consultation of an information retrieval specialist. We searched the following databases, MEDLINE (1966-December 2011), EMBASE (1980-December 2011), WEB OF SCIENCE (Science citation index-1970-December 2011), Cochrane Library up to the latest issue 2011, including the CENTRAL register of controlled trials CINHAL (Cumulative Index to Nursing \& Allied Health 1982 -December 2011) and Google Scholar. (For full search strategy see Additional file 1: Appendix 1).

We reviewed the reference lists of all relevant studies for any potential study not retrieved by the search strategy. Unpublished reports were not actively sought and there was no language limitation.

\section{Identification of included studies}

All titles and abstracts retrieved by the electronic search were screened independently by the three reviewers, and the studies which clearly did not meet the inclusion criteria, were excluded. Copies of the full text of potentially relevant studies and trials were obtained and their eligibility was assessed independently by two reviews. Differences between reviewers were resolved by discussion or by consulting the third reviewer.

\section{Data extraction and studies assessment}

Two reviews extracted data from the included studies using a designed form. The accuracy of the extracted data was checked by the third reviewer.

The Newcastle Ottawa Scale (NOS) was used for the assessment of cohort, case control studies and nonrandomized trials [10]. Risk of bias in each study, was assigned according to the number of items on the NOS judged to be inadequate. We considered low risk of bias when one item is inadequate, medium risk of bias when up to three items are inadequate and high risk of bias when more than three items are inadequate. Risk of bias of the studies included in the review was assessed for each study independently by two reviewers and any disagreement was resolved by discussion with all the reviewers.

Data analysis was carried out with the use of Review Manager Software 5.1.6 (Cochrane Collaboration, Oxford, United Kingdom).

Meta-analysis was performed for studies with similar design and type of intervention, which we assessed to be at medium or low risk of bias using the fixed effect model. Statistical heterogeneity was assessed by visual inspection of forest plots, by performing $\mathrm{x}^{2}$ tests (assessing the $\mathrm{P}$ value) and by calculating the statistic, which describes the percentage of observed heterogeneity that would not be expected by chance. If the P value was less 
than 0.10 and $\mathrm{I}^{2}$ exceeded 50\%, we considered heterogeneity to be substantial. However subgroup analysis was not possible in most of the cases due to the small number of studies. Pooled data were presented as risk ratio (RR) with $95 \%$ confidence intervals $(95 \% \mathrm{CI})$ for dichotomous outcomes and as the means difference with 95\% confidence intervals for continuous outcomes.

\section{Results}

The search retrieved 2452 potentially relevant titles of which the full text of 54 relevant reports were reviewed (Figure 1). A total of 25 reports of 21 studies were included in this review [7,8,11-33]. (Three articles described the same cohort study with two interim $[15,16]$ and one final report [17], one study reported the outcomes for the same cohort in two articles [7,27] and two articles report the outcomes of one cohort with one interim [29] and one final report [26]).

Twenty six studies were excluded because they did not meet the inclusion criteria; two reports were of conference proceedings and in one study data were not extractable (Additional file 2: Appendix 2).
Of the included studies, only one was a controlled trial, 13 studies were prospective cohort studies, six studies were retrospective cohort studies and one was a case control study (Tables 1,2,3,4). The included studies were conducted between 1983 and 2010 in Europe and the United States of America, except for one study conducted in Israel [19].

\section{Assessment of the methodological quality of the included studies}

The cohort studies included in this review (Tables 1 \& 2) had adequate description of participants including description of some confounding factors such as the frequency of renal and vascular complications of diabetes between the PPC group and the control group. However all studies did not address the effect of the presence of confounding factors on the outcomes except for three reports which used regression analysis to evaluate the effectiveness of the PPC $[7,8,27]$.

In most of the cohort studies blinding of the control group was adequate because they were recruited after pregnancy when they attended for antenatal care, except for two studies [22,26], in which inadequate blinding of

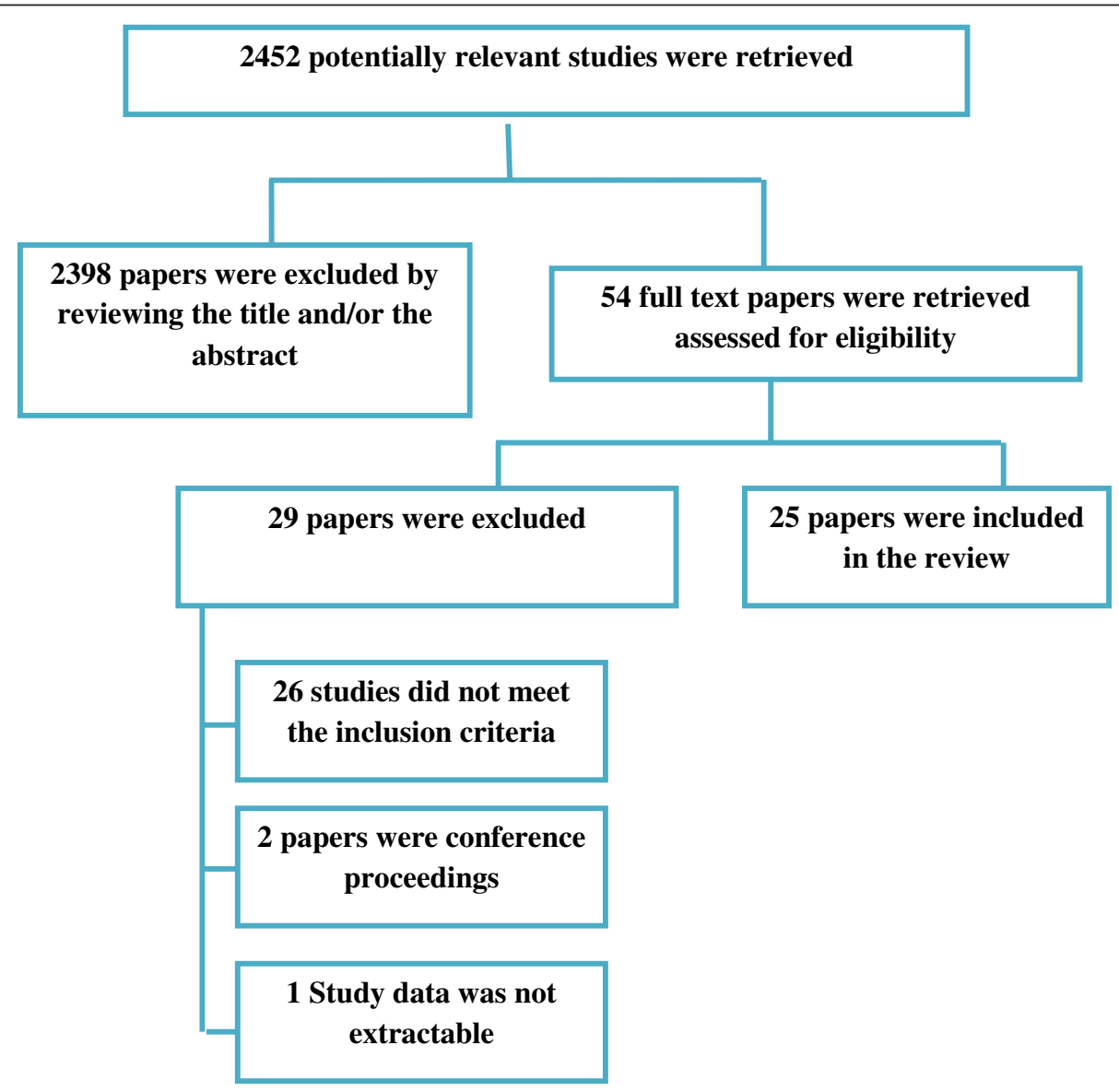

Figure 1 Process of selection of the studies for the systematic review. 
Table 1 Characteristics of included prospective cohort studies

\begin{tabular}{|c|c|c|c|c|}
\hline $\begin{array}{l}\text { Study/ Year of } \\
\text { Publication } \\
\text { Reference (country) }\end{array}$ & Participants & Intervention & Outcome & Risk of Bias (Notes) \\
\hline $\begin{array}{l}\text { Garcia-Patterson } \\
1997 \text { [18] (Spain) }\end{array}$ & $\begin{array}{l}66 \text { participants with type I and type } \\
\text { II who attended the pre-pregnancy } \\
\text { clinic and } 119 \text { participants with type I } \\
\text { and type II diabetes who did not. }\end{array}$ & $\begin{array}{l}\text { PPC included intensive insulin } \\
\text { therapy, self-monitoring of blood } \\
\text { glucose and dietary advice }\end{array}$ & $\begin{array}{l}\text { The HbA1C was significantly better in the } \\
\text { PPC group than for the NPPC group } \\
(p=0.01) \text {. } \\
\text { There was no significant difference } \\
\text { between the two groups in } \\
\text { rate of congenital malformations. }\end{array}$ & $\begin{array}{l}\text { Medium (The baseline characteristics in } \\
\text { relation to the vasculopathy are different. } \\
\text { No blinding for the outcome assessment). }\end{array}$ \\
\hline $\begin{array}{l}\text { Herman } 1999[20] \\
\text { (USA) }\end{array}$ & $\begin{array}{l}24 \text { women with type I diabetes } \\
\text { who attended the pre-pregnancy } \\
\text { clinic, and } 74 \text { women with type I } \\
\text { diabetes who did not attend the } \\
\text { pre-pregnancy clinic. }\end{array}$ & $\begin{array}{l}\text { PPC included education, } \\
\text { counseling, glycemic control, and } \\
\text { assessment of complications of } \\
\text { diabetes such as nephropathy } \\
\text { and retinopathy }\end{array}$ & $\begin{array}{l}\text { Women who had PPC had significantly } \\
\text { lower level of HbA1C at booking and } \\
\text { throughout pregnancy. There was no } \\
\text { significant difference between the two } \\
\text { groups in the frequency of infants with } \\
\text { congenital malformations. }\end{array}$ & $\begin{array}{l}\text { High (The study was not designed to assess the } \\
\text { clinical outcomes of the pre-pregnancy care but } \\
\text { the differences in the socio-demographic } \\
\text { features between the groups who attend the } \\
\text { pr-pregnancy care and those who did not. The } \\
\text { target level for the glycemic control was not } \\
\text { clear and the absolute level of Hb A1C at } \\
\text { booking and all through pregnancy for the study } \\
\text { and the control groups was not mentioned) }\end{array}$ \\
\hline $\begin{array}{l}\text { Jaffiol } 2000[21] \\
\text { (France) }\end{array}$ & $\begin{array}{l}21 \text { IDDM attended the } \\
\text { pre-conception care and } 40 \text { did } \\
\text { not attend }\end{array}$ & $\begin{array}{l}\text { PPC included education, glycemic } \\
\text { control, self monitoring of blood } \\
\text { glucose and contraception }\end{array}$ & $\begin{array}{l}\text { There were significant reductions in the } \\
\text { PM and congenital malformations in the } \\
\text { PPC group as well as in the level of } \\
\text { maternal HbA1C in the } 1^{\text {st }} \text { trimester } \\
\text { compared to the NPPC group. }\end{array}$ & $\begin{array}{l}\text { Low (good report, clear intervention description, } \\
\text { the comparative groups received same antenatal } \\
\text { intervention. No blinding for outcome } \\
\text { assessment) }\end{array}$ \\
\hline $\begin{array}{l}\text { Jensen } 1986[22] \\
\text { (Denmark) }\end{array}$ & $\begin{array}{l}9 \text { women with insulin dependent } \\
\text { diabetes had pre-pregnancy care } \\
\text { and } 11 \text { women with insulin } \\
\text { dependent diabetic who did not } \\
\text { receive pre-pregnancy care. }\end{array}$ & $\begin{array}{l}\text { PPC included continuous insulin } \\
\text { infusion initiated } 2 \text { months prior } \\
\text { to conception. }\end{array}$ & $\begin{array}{l}\text { No significant difference in congenital } \\
\text { malformations and HAb1C level, between } \\
\text { the two groups }\end{array}$ & $\begin{array}{l}\text { High (small number of study and control group, } \\
\text { many differences in the baseline characteristics } \\
\text { in the severity of diabetes, } 5 \text { of the } 11 \text { control } \\
\text { women were treated in the diabetic clinic in the } \\
\text { hospital before pregnancy so they knew about } \\
\text { the importance of glycemic control both groups } \\
\text { have the same HA1C levels in early pregnancy) }\end{array}$ \\
\hline $\begin{array}{l}\text { Kitzmiller } 1991 \\
\text { [23] (USA) }\end{array}$ & $\begin{array}{l}84 \text { women in pre-pregnancy care } \\
\text { and } 110 \text { women had no } \\
\text { pre-pregnancy care. }\end{array}$ & $\begin{array}{l}\text { PPC included glycemic and dietary } \\
\text { control education, exercise and } \\
\text { contraception. }\end{array}$ & $\begin{array}{l}\text { The frequency of congenital abnormalities } \\
\text { in the PPC group was significantly higher } \\
\text { than in the NPPC group }(p<0.05) \text {. }\end{array}$ & Low (good report clear methodology) \\
\hline $\begin{array}{l}\text { Rosenn } 1991 \\
\text { [24] (USA) }\end{array}$ & $\begin{array}{l}28 \text { women in the pre-pregnancy } \\
\text { group and } 71 \text { in the control group }\end{array}$ & $\begin{array}{l}\text { PPC included dietary advice and } \\
\text { glycemic control }\end{array}$ & $\begin{array}{l}\text { HbA1C concentration in the PPC group } \\
\text { was lower than in the NPPC group } \\
(p<0.0008) \text {. There were no congenital } \\
\text { malformations in either group. }\end{array}$ & $\begin{array}{l}\text { Medium (52\% of pre-pregnancy care patients } \\
\text { dropped out, no blinding in the assessment } \\
\text { of the outcome) }\end{array}$ \\
\hline $\begin{array}{l}\text { Temple 2006a [7] } \\
\text { 2006b [27] (UK) }\end{array}$ & $\begin{array}{l}110 \text { women with type I diabetes } \\
\text { attended the pre-pregnancy care } \\
\text { clinic and } 180 \text { women with type I } \\
\text { diabetes did not attend the } \\
\text { pre-pregnancy care clinic }\end{array}$ & $\begin{array}{l}\text { PPC included: Glycemic control, } \\
\text { folic acid supplementation, } \\
\text { smoking cessation, education. }\end{array}$ & $\begin{array}{l}\text { The rate of congenital malformations was } \\
\text { lower in PPC group compared to the NPPC } \\
\text { group }(p<0.065) \text {. PM was significantly } \\
\text { more in the latter group than the former } \\
\text { one }(p<0.026)\end{array}$ & $\begin{array}{l}\text { Low (Baseline characteristics in both groups were } \\
\text { similar; the prospective nature of the study } \\
\text { ascertained the completeness of the follow up, } \\
\text { the completeness of the baseline and the } \\
\text { outcome data. Use of appropriate statistical tests } \\
\text { such as logistic regression analysis confirmed the } \\
\text { association between the pre-pregnancy care } \\
\text { and outcomes). }\end{array}$ \\
\hline
\end{tabular}


Table 1 Characteristics of included prospective cohort studies (Continued)

Willhoite 1993

[28] (USA)

pre-pregnancy counseling and 123
women witheither type I or type II
diabetes who did not receive

pre-pregnancy counseling

\begin{tabular}{|c|c|c|c|c|}
\hline $\begin{array}{l}\text { Boulot } 2003[31] \\
\text { (France) }\end{array}$ & $\begin{array}{l}172 \text { women with either type I or } \\
\text { typell diabetes who received PPC } \\
\text { and } 260 \text { women with either type I } \\
\text { or type II diabetes who did } \\
\text { not receive PPC }\end{array}$ & $\begin{array}{l}\text { PPC included education, } \\
\text { assessment of diabetes } \\
\text { complications glycemic } \\
\text { control self monitoring of blood } \\
\text { glucose and contraception }\end{array}$ & $\begin{array}{l}\text { PPC group had significantly less PM than } \\
\text { the NPPC group, }(p<0.005) \text { for type } 1 \\
\text { diabetics and significantly less congenital } \\
\text { malformations, }(p<0.005) \text { for type } 1 \\
\text { diabetics }\end{array}$ & $\begin{array}{l}\text { Low (cases and control were well defined and } \\
\text { comparable, selection bias is unlikely as } \\
\text { consecutive cases were enrolled, the prospective } \\
\text { nature of the study ascertained the completeness } \\
\text { of the follow up, the completeness of the } \\
\text { baseline and the outcome data) }\end{array}$ \\
\hline $\begin{array}{l}\text { Galindo } 2006[30] \\
\text { (Spain) }\end{array}$ & $\begin{array}{l}15 \text { women with pre-gestational } \\
\text { diabetes received PPC and } 112 \\
\text { women with pre-gestational } \\
\text { diabetes did not receive PPC. }\end{array}$ & $\begin{array}{l}\text { PPC included education, glycemic } \\
\text { control self monitoring of } \\
\text { blood glucose }\end{array}$ & $\begin{array}{l}\text { The frequency of congenital abnormalities } \\
\text { in the PPC group was } 3 / 15 \text { compared } \\
\text { to } 14 / 112 \text { in the NPPC group. }\end{array}$ & $\begin{array}{l}\text { Low (cases and control were well defined and } \\
\text { comparable, selection bias is unlikely as } \\
\text { consecutive cases were enrolled, the prospective } \\
\text { nature of the study ascertained the completeness } \\
\text { of the follow up, the completeness of the } \\
\text { baseline and the outcome data) }\end{array}$ \\
\hline $\begin{array}{l}\text { Garcia Ingelmo } \\
1998 \text { [32] (Spain) }\end{array}$ & $\begin{array}{l}12 \text { women with pre-gestational } \\
\text { diabetes received PPC and } 12 \\
\text { women with pre-gestational } \\
\text { diabetes did not receive PPC. }\end{array}$ & PPC glycemic control. & $\begin{array}{l}\text { The frequency of congenital abnormalities } \\
\text { in the PPC group was } 3 / 12 \text { compared to } \\
2 / 12 \text { in the NPPC group. HbA1c was } \\
\text { significantly lower in the first trimester in } \\
\text { the PPC group compared to the NPPC } \\
\text { group, }(p<0.01)\end{array}$ & $\begin{array}{l}\text { High (Both the study population and the control } \\
\text { were not representative of the general diabetic } \\
\text { population with frequency of diabetic vascular } \\
\text { complications approaching } 50 \% \text {. The PPC } \\
\text { components were not defined neither the } \\
\text { target blood glucose) }\end{array}$ \\
\hline $\begin{array}{l}\text { Murphy } 2010 \\
\text { [8] (U.K) }\end{array}$ & $\begin{array}{l}181 \text { participants with type I and } \\
\text { type II who received PPC and } 499 \\
\text { participants with type I and type II } \\
\text { diabetes who did not receive PPC }\end{array}$ & $\begin{array}{l}\text { PPC included: glycemic control, } \\
\text { folic acid supplementation, } \\
\text { smoking cessation, education. }\end{array}$ & $\begin{array}{l}\text { The frequency of congenital abnormalities } \\
\text { in the PPC group was } 0.7 \% \text { compared to } \\
5.6 \% \text { in the NPPC group }(p<0.02) \text {. The PM } \\
\text { in the PPC group was } 0.7 \% \text { which was } \\
\text { similar to } 2.2 \% \text { in NPPC }(p<0.4) \text {. }\end{array}$ & Low (good report clear methodology) \\
\hline $\begin{array}{l}\text { Evers } 2004 \text { [33] } \\
\text { (Netherland) }\end{array}$ & $\begin{array}{l}271 \text { women with type I diabetes } \\
\text { had planned pregnancy and } 152 \\
\text { women did not plan their } \\
\text { pregnancy. }\end{array}$ & $\begin{array}{l}\text { PPC had planned pregnancy } \\
\text { and folic acid supplementation }\end{array}$ & $\begin{array}{l}\text { The frequency of congenital malformation } \\
\text { in PPC group was } 11 / 271(4.1 \%) \text { compared } \\
\text { to } 18 / 152(12.2 \%) \text { in the NPPC group. The } \\
\text { mean of HbA1C concentration of the PPC } \\
\text { group was significantly lower than the } \\
\text { NPPC group. }\end{array}$ & $\begin{array}{l}\text { Medium (confounding factors such as smoking, } \\
\text { education level and social class were not } \\
\text { examined.The results of HbA1C during the first } \\
\text { trimester were not available for } 29 \% \text { of the whole } \\
\text { study group) }\end{array}$ \\
\hline
\end{tabular}
Key: HbA1c = Glycosylated Hemoglobin A, PPC = Pre-pregnancy Care, NPPC = No Pre-pregnancy Care, OR= Odd Ratio, IDDM = Insulin depended Diabetes Miletus, Cl= Confidence Intervals.

PPC group had significantly less PM than the NPPC group (OR3.9 Cl 1.2-13.9) and insignificantly less congenital

malformations (OR 4.2 Cl 0.5-29.7)

health professionat the con

heath professional the contiol

had significantly less PM than diabetics

The frequency of congenital abnormalities in the PPC group was $3 / 15$ compared diabetes received PPC and 112 women with pre-gestational

PPC included education, glycer trol self monitoring of

Ine NPPC group.

The frequency of significantly lower in the first trimester in

The frequency of congenital abnormalities . group $(p<0.02)$. The PI

The frequency of congenital malformation PPC group was 11/271 (4.1\%) compared mean of $\mathrm{HbA1C}$ concentration of the PPC Wh (Base line characteristics of the two groups were significantly different in age, duration of for the outcomes. The two groups did not receive the same antenatal intra-partum and postnatal care The assessor of the congenita

(cases and control were well defined

the prospective completeness baseline and the outcome data)

OW (cases and control were well defined and consecutive cases were enrolled the prospective nature of the study ascertained the completeness complications approaching 50\%. The PPC

Low (good report clear methodology)

Medium (confounding factors such as smoking 
Table 2 Characteristics of included retrospective cohort studies

\begin{tabular}{|c|c|c|c|c|}
\hline $\begin{array}{l}\text { Study/ Year of } \\
\text { Publication } \\
\text { Reference (country) }\end{array}$ & Participants & Intervention & Outcome & Risk of Bias \\
\hline $\begin{array}{l}\text { Dunne } 1999 \\
\text { [14] (UK) }\end{array}$ & $\begin{array}{l}\text { 47women with IDDM } \\
12 \text { of them attended } \\
\text { pre-pregnancy care clinic } \\
\text { and } 35 \text { women did not. }\end{array}$ & $\begin{array}{l}\text { PPC included assessment } \\
\text { of diabetes complications } \\
\text { and glycemic control }\end{array}$ & $\begin{array}{l}\text { The PPC group had significantly } \\
\text { lower level of HA1C level } \\
\text { compared to the NPPC group } \\
(p<0.008) \text {. } \\
\text { There were no congenital } \\
\text { malformations in both groups. }\end{array}$ & $\begin{array}{l}\text { Medium (Due to the audit nature } \\
\text { of the report there is no clear } \\
\text { description of the intervention, } \\
\text { some important confounders } \\
\text { were not addressed such as } \\
\text { White's classification and the } \\
\text { outcome assessment was } \\
\text { not blinded) }\end{array}$ \\
\hline $\begin{array}{l}\text { Damm } 1989 \\
\text { [13] (Denmark) }\end{array}$ & $\begin{array}{l}197 \text { attended PPC } \\
\text { and } 61 \text { didn't attend }\end{array}$ & $\begin{array}{l}\text { PPC included: } \\
\text { contraception and } \\
\text { glycemic control. }\end{array}$ & $\begin{array}{l}\text { The rate of congenital } \\
\text { malformations was significantly } \\
\text { lower in the PPC group } 1.0 \% \\
\text { than the NPPC group } 8.2 \% \\
(p<0.01) \text {. } \\
\text { No significant difference in the } \\
\text { level of HA1C during the first } \\
\text { trimester between the two group }\end{array}$ & $\begin{array}{l}\text { High (unclear description of the } \\
\text { participants, the intervention and } \\
\text { the outcome, the data of the } \\
\text { pre-pregnancy care were a subset } \\
\text { of from different periods of the } \\
\text { study) }\end{array}$ \\
\hline $\begin{array}{l}\text { Goldman } 1986 \\
\text { [19] (Israel) }\end{array}$ & $\begin{array}{l}44 \text { women with type I } \\
\text { diabetes attended the } \\
\text { pre-pregnancy clinic } \\
\text { and } 31 \text { women with } \\
\text { type I diabetes } \\
\text { did not attend }\end{array}$ & $\begin{array}{l}\text { PPC included assessment } \\
\text { of diabetic complications, } \\
\text { Contraception advice, } \\
\text { Glycemic control and } \\
\text { dietary advice }\end{array}$ & $\begin{array}{l}\text { The NPPC group had } 3 \text { infants } \\
\text { with congenital abnormalities } \\
\text { while the PPC did have any } \\
\text { infant with congenital } \\
\text { abnormalities }\end{array}$ & $\begin{array}{l}\text { Low (Clear description of } \\
\text { participants and intervention, } \\
\text { noted confounding factors and } \\
\text { well presented results. There was } \\
\text { significant difference between } \\
\text { the two groups in the diabetes } \\
\text { complications before intervention) }\end{array}$ \\
\hline $\begin{array}{l}\text { Fuhrmann } 1986 \\
{[17] \& 1984[16] \&} \\
1983[15] \\
\text { (Germany) }\end{array}$ & $\begin{array}{l}620 \text { pregnant women } \\
\text { with insulin dependent } \\
\text { diabetes, } 183 \text { received } \\
\text { pre-pregnancy care } \\
437 \text { women did not }\end{array}$ & $\begin{array}{l}\text { PPC included: short } \\
\text { hospitalization every } \\
3 \text { month until conception, } \\
\text { education, self monitoring } \\
\text { of blood glucose, assessment } \\
\text { and treatment of diabetes } \\
\text { complications and } \\
\text { glycemic control }\end{array}$ & $\begin{array}{l}\text { PPC group had significantly } \\
\text { lower rate of congenital } \\
\text { malformations } 1.1 \% \\
\text { compared to the NPPC group } \\
7.0 \%(p<0.01)\end{array}$ & $\begin{array}{l}\text { Medium (Well described } \\
\text { intervention, no blinding for the } \\
\text { outcome, no description of the } \\
\text { possible confounding factors) }\end{array}$ \\
\hline $\begin{array}{l}\text { Rowe } 1987 \\
\text { [25] (UK) }\end{array}$ & $\begin{array}{l}21 \text { IDDM } 14 \text { received } \\
\text { pre-pregnancy care } \\
\text { and } 7 \text { did not }\end{array}$ & $\begin{array}{l}\text { PPC included } \\
\text { glycemic control, counseling } \\
\text { and blood glucose } \\
\text { self monitoring }\end{array}$ & $\begin{array}{l}\text { The PPC group had } \\
\text { significantly better initial } \\
\text { HA1C level }(p<0.0001) \text {. }\end{array}$ & $\begin{array}{l}\text { High (Unclear description of } \\
\text { the participants, no description } \\
\text { of possible confounding factors, } \\
\text { no blinding in assessment of the } \\
\text { outcome, small group, high } \\
\text { target of HbA1C 5-9\%) }\end{array}$ \\
\hline $\begin{array}{l}\text { Steel } 1990[26] \\
\& 1982[29] \\
\text { (UK- Scotland) }\end{array}$ & $\begin{array}{l}143 \text { IDDM women } \\
\text { attended the } \\
\text { pre-pregnancy } \\
\text { care clinic and } 96 \text { IDDM } \\
\text { women did not attend }\end{array}$ & $\begin{array}{l}\text { PPC included: education, } \\
\text { glycemic controlled } \\
\text { and contraception }\end{array}$ & $\begin{array}{l}\text { PPC group had lower first } \\
\text { trimester HbA1C as compared } \\
\text { to NPPC group }(p<0.0001) \\
\text { and lower rate of congenital } \\
\text { malformations }(p<0.005) \text {, } \\
\text { maternal hypoglycemia was } \\
\text { significantly common in the } \\
\text { PPC group than the NPPC } \\
(p<0.001)\end{array}$ & $\begin{array}{l}\text { Medium (Good description } \\
\text { of interventions, contamination } \\
\text { of the control who might know } \\
\text { about the usefulness of the and } \\
\text { the outcome assessment } \\
\text { was not blinded) }\end{array}$ \\
\hline
\end{tabular}

the control group cannot be excluded because they were informed about the importance of the PPC and were invited to attend. All participants received the same antenatal and post natal care except for one study [22] where participants were followed up in different health settings.

All cohort studies had adequate follow up for participants except for two studies; in one study 52\% of the PPC group were lost to follow up and in the other study $29 \%$ of records of $\mathrm{HbA} 1 \mathrm{C}$ in the first trimester for the study cohort were missing [24,33]. The assessors of the outcomes were not blinded to the participants' allocation except in one study [23].
Some of the studies at high risk of bias were initially designed to assess aspects of PPC other than its effectiveness in improving maternal and fetal outcomes, hence the poor methodological design when assessed with the NOS $[14,20,28]$.

PPC in all the cohort studies included control and self monitoring of blood glucose except for one which was designed to examine the effectiveness of pre-pregnancy counseling on fetal and neonatal outcomes [28]. In addition to glycemic control, four studies included screening and treatment of complications of diabetes in the PPC program $[14,17,19,20]$. Three cohort studies 
Table 3 Characteristics of included case-control studies

\begin{tabular}{|c|c|c|c|c|}
\hline $\begin{array}{l}\text { Study/ Year of Publication } \\
\text { Reference (country) }\end{array}$ & Participants & Intervention & Outcome & Risk of Bias/Notes \\
\hline Correa 2003 [12] USA & $\begin{array}{l}\text { Cases were } 3278 \text { Infants with } \\
\text { congenital malformations } \\
\text { related to diabetes. Controls } \\
\text { were } 3029 \text { infants without } \\
\text { congenital malformations. } \\
\text { Maternal diabetes and intake } \\
\text { of multivitamin were } \\
\text { evaluated as a risk factors } \\
\text { for congenital malformations }\end{array}$ & $\begin{array}{l}\text { PPC included the use } \\
\text { of multivitamin for } \\
3 \text { month before } \\
\text { conception }\end{array}$ & $\begin{array}{l}\text { The risk of congenital } \\
\text { malformations related to } \\
\text { diabetes was limited to } \\
\text { infants of } \mathrm{f} \text { diabetic } \\
\text { mothers who had not } \\
\text { taken multivitamin } \\
\text { (OR } 3.3995 \% \mathrm{Cl} \text { 1.79-8.63). } \\
\text { Mother who had taken } \\
\text { multivitamin had no increase } \\
\text { risk of congenital malformations } \\
\text { related to diabetes } \\
\text { (OR } 0.1595 \% \mathrm{Cl} 0.00-1.99 \text { ) }\end{array}$ & $\begin{array}{l}\text { Medium (clear definition } \\
\text { and selection of cases and } \\
\text { controls, and outcomes, } \\
\text { clearly defined outcome, } \\
\text { not clear if the } \\
\text { interviewers were blinded } \\
\text { to the outcome, recall } \\
\text { bias cannot be excluded } \\
\text { during the interviews) }\end{array}$ \\
\hline
\end{tabular}

Key: PPC = Pre-pregnancy Care, OR= Odd Ratio, $\mathrm{Cl}=$ Confidence Interval.

(four reports) had comprehensive PPC program including, control and self monitoring of blood glucose, folic acid supplementation, smoking cessation advice and discontinuation of teratogenic drugs $[7,8,27,33]$.

One case-control study was included in this review [12] (Table 3). It examined the effectiveness of multivitamin supplementation in the pre-pregnancy period in preventing diabetes related CM. The study is at medium risk of bias due to possibility of recall bias during the interview of the mothers and the possibility that interviewers were not blinded to the outcome.

One trial was included in this review [11] (Table 4). The design of the trial was not clear as authors reported it as a randomized trial but the method for randomization was not described. There was no allocation concealment and lack of blinding introduced bias because both groups were aware of the importance of the glycemic control and the complications of diabetes during pregnancy.

Only two studies in this review evaluated maternal hypoglycemia, as an adverse effect of PPC [7,26].

\section{Outcome of PPC}

Similarity of participants, interventions and outcomes in addition to the score of low or medium risk of bias, made meta-analysis possible for 13 cohort studies $[7,8,14,17-19,21,23,24,26,30,31,33]$ with 3411 participants
(Tables 1, 2 \& 5). Both dichotomous and continuous data were pooled but only when standard deviation and similar units were available for continuous data. Studies which were at high risk of bias or of a design other than cohort were excluded from the meta-analysis.

Meta-analysis suggested that pre-pregnancy care is effective in reducing CM, RR 0.25 (95\% CI 0.16-0.37), NNT19 (95\% CI 14-24) (Figure 2), and PM RR 0.34 (95\% CI 0.15-0.75), NNT $=46$ (95\% CI 28-115) (Figure 3). There was no evidence of statistical heterogeneity.

Meta-analysis of pooled data showed that PPC lowers $\mathrm{HbA} 1 \mathrm{C}$ in the first trimester of pregnancy by an average of $1.92 \%$ (95\% CI 1.79-2.05) and while there is high heterogeneity $\left(\mathrm{I}^{2}=98 \%\right)$ this variation is in the size of the effect rather than the direction (Figure 4).

The use of multivitamins in the pre-pregnancy period as a sole intervention, was evaluated by one case control study [12] and was found not to be effective in reducing the rate of CM, [Odd Ratio (OR) 0.15, 95\% CI 0.00-1.99].

Similarly one study, at high risk of bias, evaluated the effectiveness of pre-pregnancy counseling, as a sole intervention, in improving fetal and neonatal outcomes, showed improvement in PM, OR 3.9(95\% CL $1.2-13.9)$ and no improvement in the rate of CM, OR 4.2(95\% CL 0.5-29.7) [28].

Hypoglycemia as an adverse effect of PPC was evaluated by two studies [7,26]. Meta-analysis of the pooled data

Table 4 Characteristics of included controlled trials

\begin{tabular}{|c|c|c|c|c|}
\hline $\begin{array}{l}\text { Study/ Year of } \\
\text { PublicationReference } \\
\text { (country) }\end{array}$ & Participants & Intervention & Outcome & Risk of Bias/Note \\
\hline $\begin{array}{l}\text { Pregnancy outcome } \\
\text { in Diabetes control } \\
\text { and complication } \\
\text { trial research group } \\
1996 \text { [11] (USA) }\end{array}$ & $\begin{array}{l}187 \text { had pre-pregnancy } \\
\text { intensive insulin therapy } \\
\text { and } 83 \text { did not. }\end{array}$ & $\begin{array}{l}\text { PPC included } \\
\text { glycemic control } \\
\text { and dietary } \\
\text { advice. }\end{array}$ & $\begin{array}{l}\text { There was one still birth in the } \\
\text { PPC group and } 3 \text { in the NPPC. } \\
\text { Congenital malformations were } \\
5 \text { in the PPC group and } 4 \text { in the } \\
\text { NPPC group. Mean HbA } 1 C \text { in PPC } \\
\text { group was } 7.4 \pm 1.3 \text { compared } \\
\text { to } 8.8 \pm 1.7 \text { in the NPPC group. }\end{array}$ & $\begin{array}{l}\text { High (Unclear report of the outcome, } \\
\text { the control group was aware of the } \\
\text { importance of glycemic control and } \\
\text { was repeatedly advised to change into } \\
\text { intensive therapy when planning pregnancy. } \\
\text { So intervention was not restricted to the } \\
\text { pre-pregnancy group. No specific target } \\
\text { level of the blood sugar was stated for the } \\
\text { pre-pregnancy group) }\end{array}$ \\
\hline
\end{tabular}


Table 5 Pooled estimates effect of pre-pregnancy care

\begin{tabular}{lll}
\hline Dichotomous outcomes of pre-pregnancy care & No of studies [reference] & Risk Ratio [95\% Confidence interval] \\
\hline Congenital malformation & $13[7,8,14,17-19,21,23,24,26,30,31,33]$ & $0.25[0.16-0.37]$ \\
\hline PM & $6[7,8,14,18,21,31]$ & $0.34[0.15-0.75]$ \\
\hline Maternal hypoglycemia & $2[7,26]$ & $1.51[1.15,1.99]$ \\
\hline Continuous outcomes & Number of studies references & Means difference (95\% Cl) \\
\hline The difference in the level of glycosylated Hemoglobin A1C & $5[7,19,24,26,33]$ & $-2.43[-2.27$ to -2.58$]$ \\
\hline
\end{tabular}

showed that women who received PPC had significantly more frequent hypoglycemia than those who did not, RR 1.51 (95\% CI 1.15-1.99) (Figure 5). However this outcome is associated with marked heterogeneity $\left(\mathrm{I}^{2}=85 \%\right)$.

\section{Discussion}

In this review PPC reduced the rate of CM from $7.4 \%$ to 1.9\%; a rate similar to that reported for the background population (Figure 2).

Reports from practically implemented PPC programs support our findings of the effectiveness of PPC in improving the rate of $\mathrm{CM}$ of infants of mothers with PGDM [8,33]. However, many uncertainties remain about the ability of these programs to reduce the malformation rate to that of the background population, particularly that a small but significant risk of $\mathrm{CM}$ remained [33,34]. This observation might be due to many factors, for instance the preferential effect of the PPC on women with type 2 diabetes [8,35]; the influence of other maternal risk factors for $\mathrm{CM}$, such as maternal obesity [36]; and the degree of comprehensiveness; and coverage of services the program provides to prevent malformations beside glycemic control, such as folic acid supplementation and discontinuing teratogenic medication [8].

Population based studies showed a variable increase of 2.5 - 9 folds in the PM rate in diabetic mothers compared to the background population [37]. For women with PGDM $16-28 \%$ of PM is due to CM, and an additional $21-41 \%$ is due to preterm delivery $[38,39]$. Since the rates of both complications improve with PPC [9], it is not surprising that the PM in women, who attended PPC, in this review, is reduced by $66 \%$ compared to those who did not (Figure 3).

During the period of organogenesis, maternal hyperglycemia is known to be associated with CM [34,40]. Population based studies showed a linear relationship between maternal $\mathrm{HbA1C}$ level above $7 \%$, in the first trimester, and both CM and PM [41]. It is estimated that an increase of $1 \%$ in the level of HbA1C in the first trimester increases the odds of an adverse pregnancy outcome by $5-6 \%[42]$.

The analysis of the pooled data in this review suggested that PPC is effective in reducing the level of

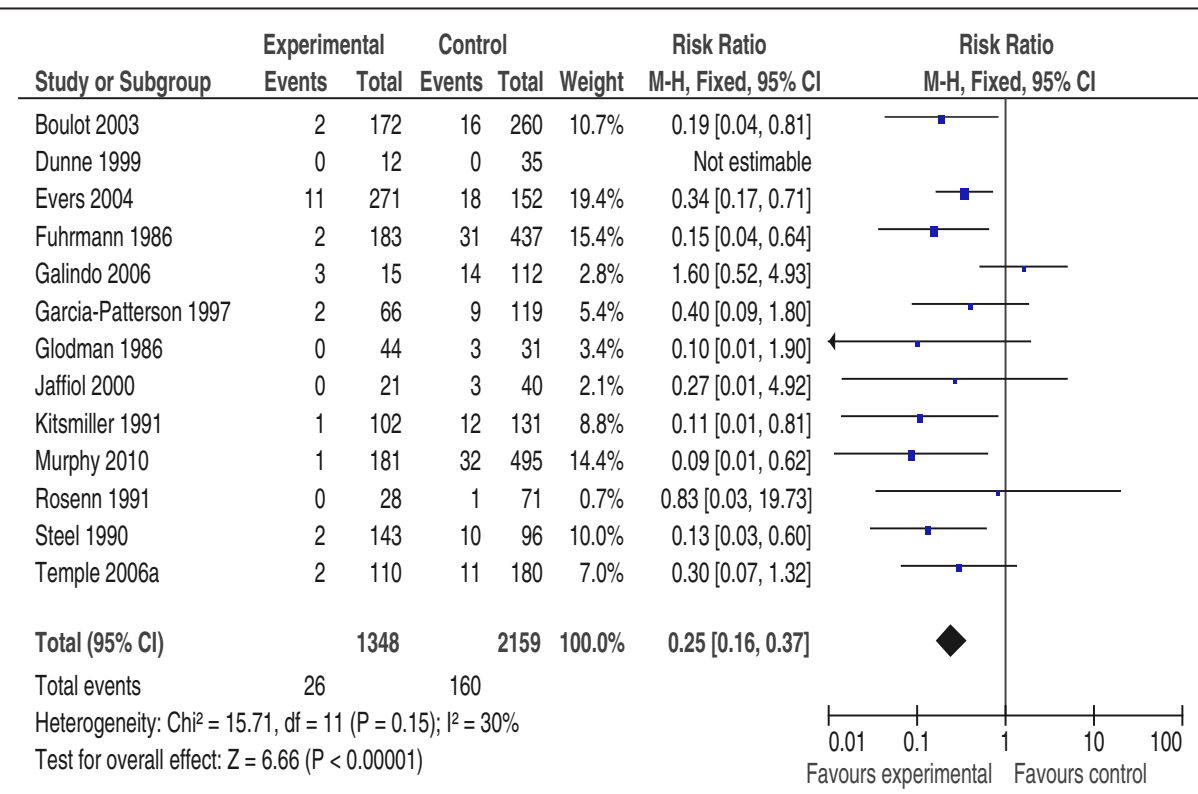

Figure 2 Risk Ratio for congenital malformation from 13 studies of women with pre-gestational diabetes mellitus who did or did not receive pre-pregnancy care. PPC (experimental) = the group who received pre-pregnancy care; NPPC (control) = the group who did not received pre-pregnancy care; $\mathrm{Cl}=$ Confidence intervals. 


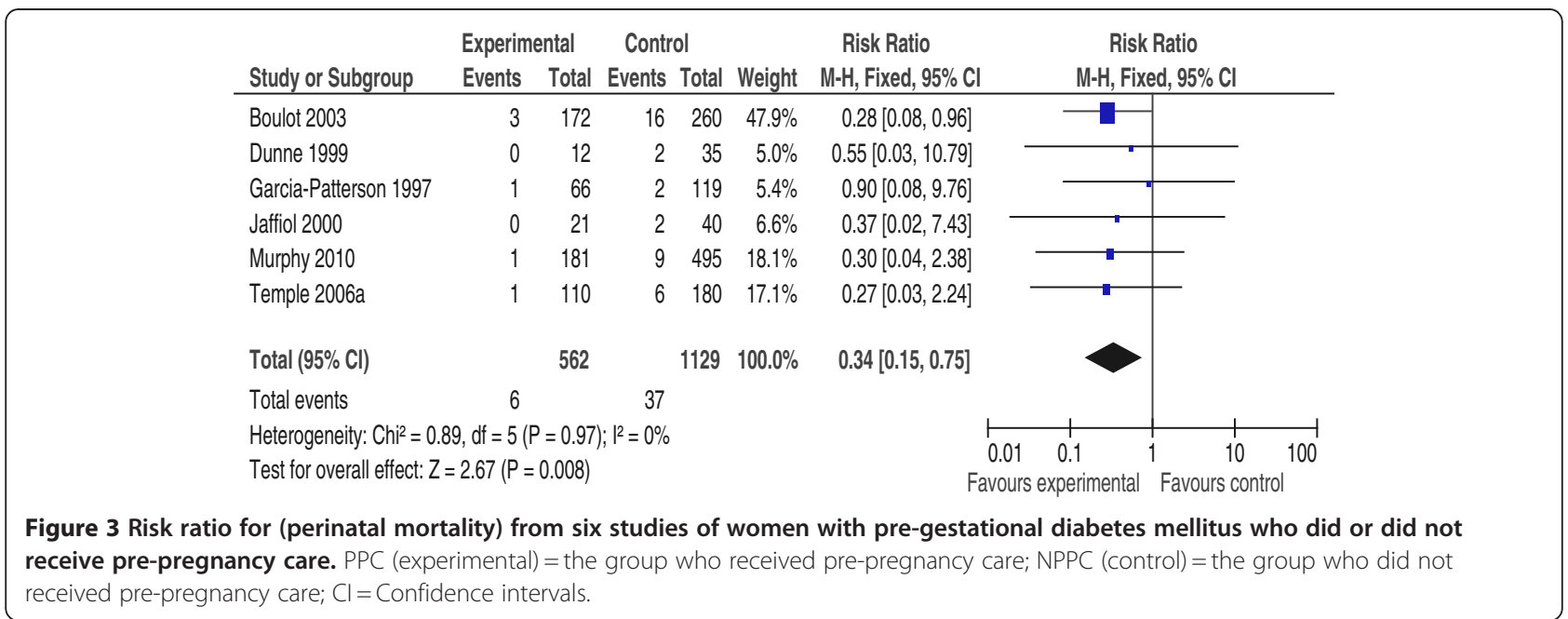

HbA1C during the first trimester of pregnancy by $1.9 \%$ (Figure 4). However this result is associated with marked statistical heterogeneity $\left(\mathrm{I}^{2}=98 \%\right)$ (Figure 4$)$. The reason for this heterogeneity is the difference in 'effect size' produced by the PPC between the included studies. Evers et al. reported a reduction of $8.5 \%$ in $\mathrm{HbA1C}$ between the intervention and the control groups [33], while Goldman et al. documented a reduction of $29 \%$ [19]. Another reason is the difference in the mean levels of HbA1C of the intervention groups (target level), which vary between $6.4 \%$ [33] and 8.5\% [24,26]. Nevertheless the overall estimate of the effect of PPC in reducing the level of $\mathrm{HbA} 1 \mathrm{C}$ is evident by the same direction of effect in all included studies (Figure 4).

In the two studies that evaluated severe maternal hypoglycemia as an adverse effect of PPC $[7,26]$ the pooled data showed an increased risk of hypoglycemia in women who attended the PPC as compared to those who did not (Figure 5). However, this result should be approached with caution due to the marked statistical heterogeneity associated with the meta-analysis $\left(\mathrm{I}^{2}=85 \%\right)$ (Figure 5) and the small number of included studies. The most likely explanation of the statistical heterogeneity is the variable effect size of PPC on maternal hypoglycemia in the two studies. The study by Temple et al. [7] showed no effect of PPC on maternal hypoglycemia, RR 1.18 (95\% CI 0.88-1.58), while the study by Steel et al. showed a significant increase in hypoglycemia among women who attended PPC RR 3.19 (95\% CI 1.56-6.53) (Figure 5). We believe that the statistical heterogeneity is a reflection of a true clinical heterogeneity. During the 16 year interval between the two studies (Steel et al. 1990, Temple et al. 2006) many innovations in the treatment of diabetes in pregnancy have been developed. Such innovations included patients' education and counseling, intensive self-monitoring of blood glucose and functional insulin therapy [43]. Although meta-analysis suggested an increased risk of severe hypoglycemia with PPC, we believe this is an unlikely adverse effect with modern treatment and monitoring of diabetes during pregnancy.

In this review some isolated interventions in the prepregnancy period were not as effective as a 'program of interventions'. One case control study addressed the effectiveness of multivitamin supplementation in the prepregnancy period, as an isolated intervention, in reducing the rate of CM and showed no effectiveness [12].

One study conducted an economic evaluation of PPC and found that it is associated with considerable savings,

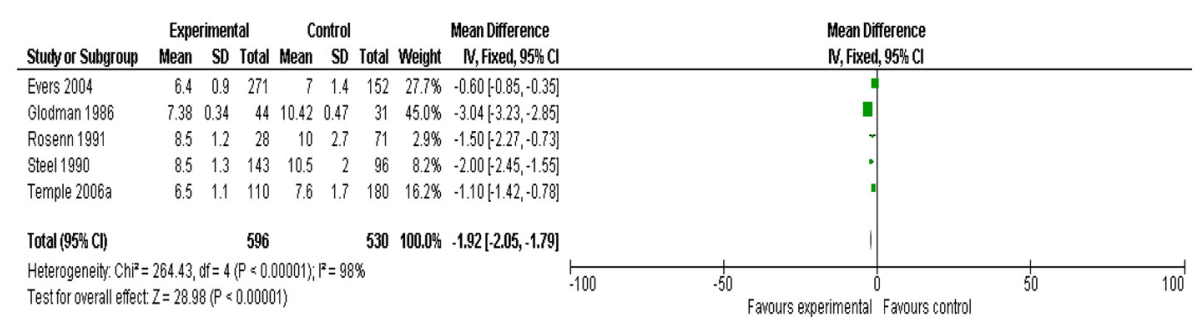

Figure 4 First trimester mean value of glycosylated hemoglobin A1C from five studies of women with pre-gestational diabetes mellitus who did or did not receive pre-pregnancy care. PPC (experimental) = the group who received pre-pregnancy care; NPPC $($ control) $=$ the group who did not received pre-pregnancy care; $\mathrm{Cl}=$ Confidence intervals. 


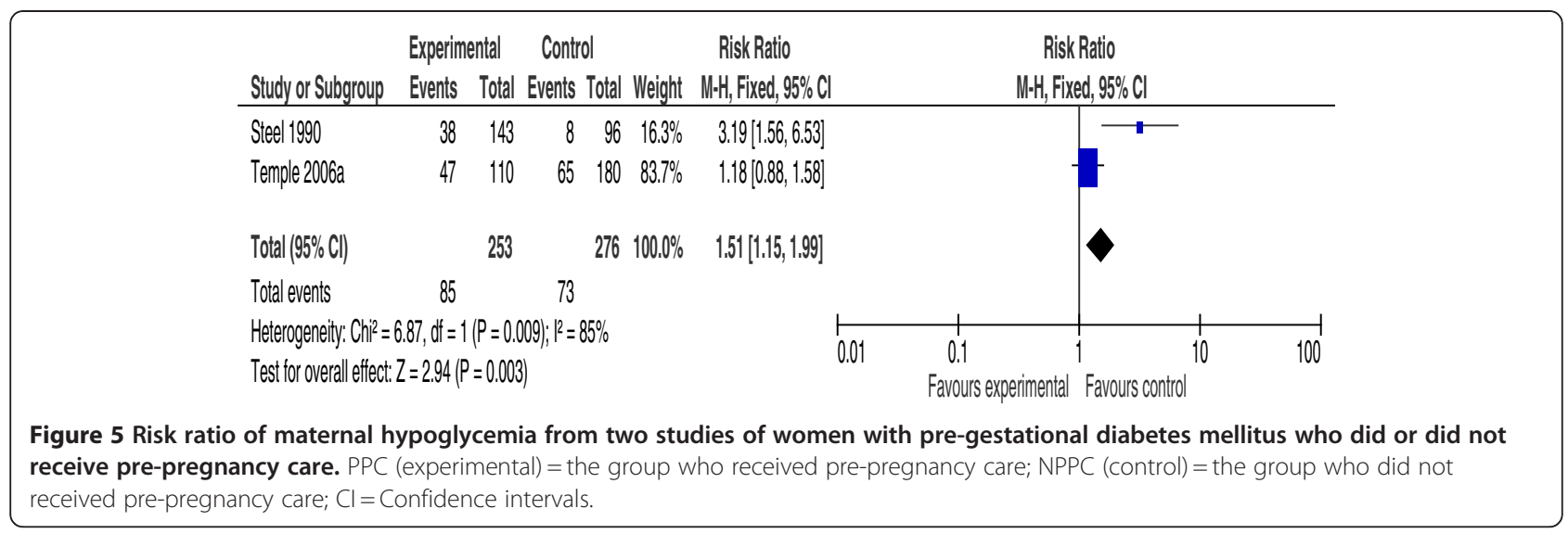

and reduced resource utilization [20]. However, population based studies showed that only $34-38 \%$ of eligible women receive PPC $[3,28]$. Hence further studies should focus on how to increase utilization and uptake of PPC and reduction of the rate of unplanned pregnancies among diabetic women.

This systematic review provides a moderate to high level of evidence for the effectiveness of PPC in the improvement of maternal and fetal outcomes [44]. It confirms previous findings by Ray et al. [6]; nevertheless, the strength of our review is based on the comprehensive evaluation of the available evidence on the effectiveness and safety of PPC.

We are aware of the limitations of the observational studies as the main source of evidence and the inherent bias associated with the design; however, randomized controlled trials to assess the effectiveness of PPC are neither ethical nor feasible. Nevertheless the nature of the intervention lent strength to the observational studies by avoiding certain biases known to occur in such study designs. Lack of allocation concealment and blinding of participants were avoided by recruiting the intervention and the control groups at different times during the course of the study (pre-pregnancy period and antenatal period). Additionally, and due to the relatively short duration of the pregnancy, attrition bias was noted in only one study, [24] all other studies had complete follow-up of both groups. The possible bias due to confounding factors such as social class, level of education, subjects' motivation, smoking, maternal age, obesity, parity and vascular complications of diabetes, was noted by most of the studies but only two studies used the appropriate statistical tests to quantify the effect of the PPC apart from the confounders $[7,8]$. It is worth noting that all but one of the studies included in this review were conducted in Europe and the United States of America [19], which limits the generalizability of this review.

The review carries important implications for practice and research as it highlights the importance of the integration of PPC in the routine care of diabetic women during their reproductive age. and have practical implication considering the recent report of the $\mathrm{CEMCH}$ [3] which showed that $\mathrm{CM}$ rate in infants of diabetic mothers in England, Wales and Northern Ireland is twofold, and the PM was nearly fourfold, that of the background population. These findings are also of a paramount importance to many communities in the Middle East [45], North Africa [46] and some communities in Asia [47] where the rate of CM is very high due to many causes including maternal diabetes.

One of the main obstacles to the full implementation of PPC programs is the failure of the target population to utilize provided services [8]. We suggest that more research is needed in methods of encouraging diabetic women to utilize PPC.

\section{Conclusion}

PPC for women with type 1 or type 2 PGDM is effective in improving rates of $\mathrm{CM}, \mathrm{PM}$ and in reducing maternal $\mathrm{HbA} 1 \mathrm{C}$ in the first trimester of pregnancy. PPC might cause maternal hypoglycemia in the first trimester of pregnancy.

\section{Additional files}

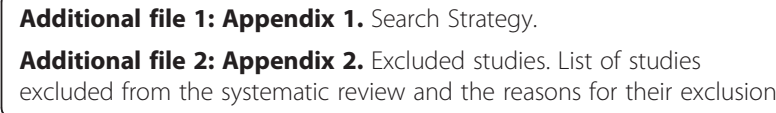

Competing interests

The authors declare that they have no competing interest.

\section{Authors' contribution}

HW conceived the idea of the review, was responsible for drafting and writing the study protocol and reviewing the search strategy. HW, RZ and SE were responsible for study selection and data extraction. HW and RZ were responsible for quality assessment of studies and data analysis. HW was responsible for writing the final manuscript. HW, RZ and SE reviewed and approved the final manuscript. 


\section{Acknowledgement}

We acknowledge the assistance of Dr Amel Fayed for helping with the statistics of this review and Mr. Gordon Arnold for his help with the language editing of the manuscript.

\section{Funding}

There was no funding body; the review was done as part of the activities of Sheikh Bahmdan Chair of Evidence-based Healthcare and Knowledge Translation. College of Medicine, King Saud University.

Received: 26 April 2012 Accepted: 14 September 2012

Published: 17 September 2012

\section{References}

1. Ray JG, Vermeulen MJ, Meier C, Wyatt PR: Risk of congenital anomalies detected during antenatal serum screening in women with pregestational diabetes. QJM 2004, 97:651-653.

2. Wren C, Birrell G, Hawthorne G: Cardiovascular malformations in infants of diabetic mothers. Heart 2003, 89:1217-1220.

3. Confidential Enquiry into Maternal and Child Health (CEMACH): Pregnancy in Women with type 1 and type 2 Diabbetes in 2002-2003. England, Wales and Northern Ireland. London: CEMACH; 2005.

4. Reece EA: Maternal fuels, diabetic embryopathy: pathomechanisms and prevention. Semin Reprod Endocrinol 1999, 17:183-194.

5. Mathiesen ER, Ringholm L, Damm P: Stillbirth in diabetic pregnancies. Best Pract Res Clin Obstet Gynaecol 2011, 25:105-111.

6. Ray JG, O'Brien TE, Chan WS: Pre-pregnancy care and the risk of congenital anomalies in the offspring of women with diabetes mellitus: a meta-analysis. QJM 2001, 94:435-444.

7. Temple RC, Aldridge VJ, Murphy HR: Prepregnancy care and pregnancy outcomes in women with type 1 diabetes. Diabetes Care 2006 29:1744-1749.

8. Murphy HR, Roland JM, Skinner TC, Simmons D, Gurnell E, Morrish NJ, et al: Effectiveness of a regional prepregnancy care program in women with type 1 and type 2 diabetes: benefits beyond glycemic control. Diabetes Care 2010, 33:2514-2520.

9. Wahabi HA, Alzeidan RA, Bawazeer GA, Alansari LA, Esmaeil SA: Preconception care for diabetic women for improving maternal and fetal outcomes: a systematic review and meta-analysis. BMC Pregnancy Childbirth 2010, 10:63.

10. Well GA, Shea B, C'Connell D, Peterson J, Welch V, Losos M, et al: The NewcaslteOttawa Scal (NOS) for assessing the quality of nonrandomised studies in metanalyses. 2005. http://www.ohri.ca/programs/clinical_epidemiology/oxford.asp.

11. DCCT Study Group: Pregnancy outcomes in the Diabetes Control and Complications Trial. Am J Obstet Gynecol 1996, 174:1343-1353.

12. Correa A, Botto L, Liu Y, Mulinare J, Erickson JD: Do multivitamin supplements attenuate the risk for diabetes-associated birth defects? Pediatrics 2003, 111:1146-1151.

13. Damm P, Molsted-Pedersen L: Significant decrease in congenital malformations in newborn infants of an unselected population of diabetic women. Am J Obstet Gynecol 1989, 161:1163-1167.

14. Dunne FP, Brydon P, Smith T, Essex M, Nicholson H, Dunn J: Preconception diabetes care in insulin-dependent diabetes mellitus. QJM 1999, 92:175-176

15. Fuhrmann $\mathrm{K}$, Reiher $\mathrm{H}$, Semmler K, Fischer F, Fischer M, Glockner E: Prevention of congenital malformations in infants of insulin-dependent diabetic mothers. Diabetes Care 1983, 6:219-223.

16. Fuhrmann $\mathrm{K}$, Reiher $\mathrm{H}$, Semmler $\mathrm{K}$, Glockner $\mathrm{E}$ : The effect of intensified conventional insulin therapy before and during pregnancy on the malformation rate in offspring of diabetic mothers. Exp Clin Endocrinol 1984, 83:173-177.

17. Fuhrmann K: Treatment of pregnant insulin-dependent diabetic women. Acta Endocrinol Suppl (Copenh) 1986, 277:74-76.

18. Garcia-Patterson A, Corcoy R, Rigla M, Caballero A, Adelantado JM, Altirriba $O$, et al: Does pre-preconceptional counselling in diabetic women influence perinatal outcome? Ann Ist Super Sanita 1997, 33:333-336.

19. Goldman JA, Dicker D, Feldberg D, Yeshaya A, Samuel N, Karp M: Pregnancy outcome in patients with insulin-dependent diabetes mellitus with pre-preconceptional diabetic control: a comparative study. Am J Obstet Gynecol 1986, 155:293-297.
20. Herman WH, Janz NK, Becker MP, Charron-Prochownik D: Diabetes and pregnancy. Pre-conception care, pregnancy outcomes, resource utilization and costs. J Reprod Med 1999, 44:33-38.

21. Jaffiol C, Baccara MT, Renard E, Apostol DJ, Lefebvre P, Boulot P, et al: [Evaluation of the benefits brought by pregnancy planning in type 1 diabetes mellitus]. Bull Acad Natl Med 2000, 184:995-1007.

22. Jensen BM, Kuhl C, Molsted-Pedersen L, Saurbrey N, Fog-Pedersen J: prepreconceptional treatment with insulin infusion pumps in insulindependent diabetic women with particular reference to prevention of congenital malformations. Acta Endocrinol Suppl (Copenh) 1986, 277:81-85

23. Kitzmiller JL, Gavin LA, Gin GD, Jovanovic-Peterson L, Main EK, Zigrang WD: pre-conception care of diabetes Glycemic control prevents congenital anomalies. JAMA 1991, 265:731-736.

24. Rosenn B, Miodovnik M, Combs CA, Khoury J, Siddiqi TA: Pre-conception management of insulin-dependent diabetes: improvement of pregnancy outcome. Obstet Gynecol 1991, 77:846-849.

25. Rowe BR, Rowbotham CJ, Barnett AH: Pre-conception counselling, birth weight, and congenital abnormalities in established and gestational diabetic pregnancy. Diabetes Res 1987, 6:33-35.

26. Steel JM, Johnstone FD, Hepburn DA, Smith AF: Can prepregnancy care of diabetic women reduce the risk of abnormal babies? BMJ 1990, 301:1070-1074.

27. Temple RC, Aldridge V, Stanley K, Murphy HR: Glycaemic control throughout pregnancy and risk of pre-eclampsia in women with type I diabetes. BJOG 2006, 113:1329-1332

28. Willhoite MB, Bennert HW Jr, Palomaki GE, Zaremba MM, Herman WH, Williams JR, et al: The impact of preconception counseling on pregnancy outcomes. The experience of the Maine Diabetes in Pregnancy Program. Diabetes Care 1993, 16:450-455.

29. Steel JM, Johnstone FD, Smith AF, Duncan LJP: Five years' experience of "prepregnancy" clinic for insulin-dependent diabetics. BMJ 1982, 285:353-356.

30. Galindo A, Burguillo AG, Azriel S, Fuente PL: Outcome of fetuses in women with pregestational diabetes mellitus. J Perinat Med 2006, 34:323-331.

31. Boulot $P$, Chabbert-Buffet $N$, d'Ercole C, Floriot M, Fontaine P, Fournier A, et al: French multicentric survey of outcome of pregnancy in women with pregestational diabetes. Diabetes Care 2003, 26:2990-2993.

32. Garcia Ingelmo MT, Herranz dM, Martin VP, Janez FM, Grande AC, Pallardo Sanchez LF: [Pre-preconceptional control in diabetic women]. Rev Clin Esp 1998, 198:80-84.

33. Evers IM, de Valk HW, Visser GH: Risk of complications of pregnancy in women with type 1 diabetes: nationwide prospective study in the Netherlands. BMJ 2004, 328:915.

34. Corrigan N, Brazil DP, McAuliffe F: Fetal cardiac effects of maternal hyperglycemia during pregnancy. Birth Defects Res A Clin Mol Teratol 2009, 85:523-530.

35. Persson $M$, Norman $M$, Hanson U: Obstetric and perinatal outcomes in type 1 diabetic pregnancies: A large, population-based study. Diabetes Care 2009, 32:2005-2009.

36. Persson M, Pasupathy D, Hanson U, Westgren M, Norman M: Prepregnancy body mass index and the risk of adverse outcome in type 1 diabetic pregnancies: a population-based cohort study. BMJ Open 2012, 2:e000601

37. Melamed N, Hod M: Perinatal mortality in pregestational diabetes. Int J Gynaecol Obstet 2009, 104(Suppl 1):S20-S24.

38. Jensen DM, Damm P, Moelsted-Pedersen L, Ovesen P, Westergaard JG, Moeller $M$, et al: Outcomes in type 1 diabetic pregnancies: a nationwide, population-based study. Diabetes Care 2004, 27:2819-2823.

39. Platt MJ, Stanisstreet M, Casson IF, Howard CV, Walkinshaw S, Pennycook S, et al: St Vincent's Declaration 10 years on: outcomes of diabetic pregnancies. Diabet Med 2002, 19:216-220.

40. Riskin-Mashiah S, Younes G, Damti A, Auslender R: First-trimester fasting hyperglycemia and adverse pregnancy outcomes. Diabetes Care 2009, 32:1639-1643

41. Jensen DM, Korsholm L, Ovesen P, Beck-Nielsen H, Moelsted-Pedersen L, Westergaard JG, et al: Peri-conceptional A1C and risk of serious adverse pregnancy outcome in 933 women with type 1 diabetes. Diabetes Care 2009, 32:1046-1048. 
42. Nielsen GL, Moller M, Sorensen HT: HbA1c in early diabetic pregnancy and pregnancy outcomes: a Danish population-based cohort study of 573 pregnancies in women with type 1 diabetes. Diabetes Care 2006, 29:2612-2616.

43. Howorka K, Pumprla J, Gabriel M, Feiks A, Schlusche C, Nowotny C, et al: Normalization of pregnancy outcome in pregestational diabetes through functional insulin treatment and modular out-patient education adapted for pregnancy. Diabet Med 2001, 18:965-972.

44. Atkins D, Best D, Briss PA, Eccles M, Falck-Ytter Y, Flottorp S, et al: Grading quality of evidence and strength of recommendations. BMJ 2004, 328:1490.

45. Al-Gazali L, Hamamy H, Al-Arrayad S: Genetic disorders in the Arab world. BMJ 2006, 333:831-834.

46. Jaouad IC, Elalaoui SC, Sbiti A, Elkerh F, Belmahi L, Sefiani A: Consanguineous marriages in Morocco and the consequence for the incidence of autosomal recessive disorders. J Biosoc Sci 2009, 41:575-581.

47. Hussain R, Bittles AH, Sullivan S: Consanguinity and early mortality in the Muslim populations of India and Pakistan. Am J Hum Biol 2001, 13:777-787.

doi:10.1186/1471-2458-12-792

Cite this article as: Wahabi et al: Pre-pregnancy care for women with pre-gestational diabetes mellitus: a systematic review and metaanalysis. BMC Public Health 2012 12:792.

\section{Submit your next manuscript to BioMed Central and take full advantage of:}

- Convenient online submission

- Thorough peer review

- No space constraints or color figure charges

- Immediate publication on acceptance

- Inclusion in PubMed, CAS, Scopus and Google Scholar

- Research which is freely available for redistribution 